\title{
O agente comunitário de saúde não deve ser um "super-herói"
}

\author{
The community healthcare agent should not be a "super-hero"
}

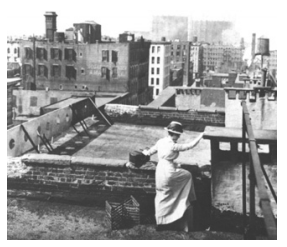

José Batista Cisne Tomaz ${ }^{1}$

A primeira experiência de agentes comunitários de saúde, ACS, como uma estratégia abrangente de saúde pública estruturada, ocorreu no Ceará em 1987, com o objetivo duplo de criar oportunidade de emprego para as mulheres na área da seca e, ao mesmo tempo, contribuir para a queda da mortalidade infantil, priorizando a realização de ações de saúde da mulher $e$ da criança. Esta estratégia expandiu-se rapidamente no Estado, atingindo praticamente todos os municípios em três anos, sendo encampada pelo Ministério da Saúde (MS) mais ou menos nos mesmos moldes, em 1991. As primeiras experiências do Programa de Saúde da Família, PSF, nos moldes atuais, também surgiram no Ceará em janeiro de 1994, sendo encampadas pelo MS em março do mesmo ano, como estratégia de reorganização da atenção básica no país. A partir daí o Programa de Agentes Comunitários de Saúde, PACS, passou a ser incorporado pelo PSF.

O PACS e o PSF, apesar do " $p$ ", não devem ser vistos como programas, $e$ sim como estratégias estruturantes, já que se propõem a reorganizar a atenção básica e não apenas aumentar a extensão de cobertura para as populações marginalizadas. O próprio artigo esclarece que os princípios $e$ pressupostos do PSF contidos em documentos do MS vão muito além da extensão da cobertura da atenção básica para a população pobre. O PACS e o PSF, embora no início tenham sido implantados prioritariamente em áreas marginalizadas, devem ser vistos como uma estratégia que, a médio e a

${ }^{1}$ Médico, Coordenador do Curso de Especialização em Saúde da Família da Escola de Saúde Pública do Ceará/ESP-Ce. <batista@esp.ce.gov.br> 
longo prazo, irá prover atenção básica em saúde para toda a população, de acordo com os princípios da integralidade, universalidade e eqüidade do sus. A reorganização da atenção básica deve também pressionar os outros níveis de atenção no sentido de que se reestruturem para atender com qualidade a demanda advinda da atenção básica. Se a concepção não for essa, sou obrigado a concordar com os críticos que dizem tratar-se de uma "cesta básica da saúde" utilizando uma "medicina pobre para os pobres" mediante ações de baixa tecnologia. Infelizmente, na prática, o trabalho de muitas equipes do PSF ainda está limitado ao aumento da extensão de cobertura, conseqüência de várias questões operacionais, mas também da falta de uma adequada qualificação dos profissionais, inclusive dos gestores.

\section{O perfil, as atribuições, $e$ as competências do ACS}

A discussão do perfil, atribuições e competências dos ACS é um pouco polêmica. Ainda não se conseguiu determiná-los de maneira clara e efetiva. $O$ artigo aborda muito bem as atribuições $e$ as competências, mas trata muito pouco sobre o perfil. Fala de um "novo" perfil profissional - um novo saber, um novo fazer, um novo ser -, mas não especifica qual seria esse novo perfil. É consenso que o ACS seja da própria comunidade, seja "alguém que se identifica, em todos os sentidos, com a sua própria comunidade, principalmente na cultura, linguagem, costumes", como afirma um ACS de Recife. O que temos de refletir é sobre o grau de escolaridade. Após a implantação do PSF o papel do ACS foi ampliado, saiu do foco maternoinfantil para a família e a comunidade, além de exigir novas competências no campo político e social. Desse modo, é necessário que o ACS tenha um grau de escolaridade mais elevado, para dar conta desse novo papel, bem mais complexo e abrangente.

Concordo plenamente com as autoras que, historicamente, uma atribuição fundamental do ACS é servir de elo entre a comunidade e o sistema de saúde. No documento do MS: Diretrizes para elaboração de programas de qualificação e requalificação dos agentes comunitários de saúde (1999), de cuja elaboração participei, é proposto um conjunto de atribuições que podem ser resumidas no tripé: identificar sinais e situações de risco, orientar as famílias e comunidade e encaminhar/ comunicar à equipe os casos e situações identificadas. Esse conjunto de atribuições deve ter como pano de fundo as questões de cunho político e social, principalmente as ligadas à competência de promoção da saúde. Achei interessante a análise das dimensões do papel do ACS em termos técnicoassistencial e político-social. No entanto, nesta discussão, estou começando a perceber duas tendências que se têm mostrado constantes nos escritos e nas falas sobre o papel do ACS, (permitam-me usar dois neologismos): a "superheroização" e a "romantização" do ACS, que está bem expresso nos depoimentos que abrem o texto de Silva e Dalmaso.

Ora, não se pode colocar nas costas do ACS o árduo e complexo papel de ser a "mola propulsora da consolidação do SUS". Na prática, a consolidação do SUS depende de um conjunto de fatores técnicos, políticos, sociais e o envolvimento de diferentes atores, incluindo os próprios ACS, que, sem 
dúvida, têm um papel fundamental. Na realidade, o ACS precisa incorporarse de fato ao sistema de saúde, fazer parte efetivamente das equipes de saúde da família, deve participar das diferentes ações, na dimensão técnicoassistencial ou político-social.

Por falta de uma clara delimitação de suas atribuições, seu papel tem sido distorcido sobrecarregando, muitas vezes, seu trabalho. Qualquer ação que deva ser desenvolvida nas famílias e na comunidade é atribuída ao ACS. Assim, a identificação de crianças fora da escola, a limpeza das caixas d'água para combater o mosquito da Dengue, a reclamação ao proprietário de uma pocilga instalada numa área urbana, tudo isso e muito mais é de responsabilidade do ACS. Isso tem implicação direta no processo inadequado de qualificação, pois passa a receber diversos micro-treinamentos, fragmentados, dados por diferentes programas, fora do contexto e sem uma seqüência lógica.

Não há a menor dúvida de que o ACS deve contribuir para o processo de transformação social. No entanto, é preciso ter em mente que a transformação social é um processo lento, requer esforços conjuntos $e$ permanentes e é papel de todos os cidadãos. O setor saúde no Brasil tem, historicamente, um papel de vanguarda nessa transformação. Por isso considero que esse processo deve envolver todos os profissionais de saúde (técnicos e gestores) e de outros setores da sociedade. Assim, a dimensão política deve ser exercida pelo ACS, não só como profissional, mas como cidadão. O que quero dizer é que esse dilema permanente no qual a dimensão social e política convive com a dimensão técnico-assistencial não é privilégio do agente, mas de todos os outros profissionais da Saúde. A dimensão técnica é necessária, deve ser exercida com qualidade, sem perder de vista a dimensão social e política. Isso vale para todos os profissionais. Considero, ainda, que as diferentes formas de atuação do ACS e da equipe de saúde não devem ser necessariamente antagônicas, mas sim complementares. A vertente de vigilância a situações de risco e assistência a doenças mais freqüentes deve ser realizada conjuntamente e em consonância com a da promoção da saúde e da qualidade de vida.

Em suma, o ACS não é e não deve ser um super-herói! Suas atribuições devem ser claramente estabelecidas, como profissional, como parte de uma equipe de saúde. Seu papel deve ser menos "romântico" e mais claro e específico.

\section{O desafio: processo de formação e qualificação}

Quando se pretende discutir processo de formação ou qualificação de recursos humanos é fundamental termos clareza de três aspectos: o perfil do profissional a ser capacitado, suas necessidades de formação $e$ qualificação e que competências devem ser desenvolvidas ou adquiridas no processo educacional. Desse modo, a complexidade e a dimensão dos desafios colocados para o processo de formação e qualificação do ACS estão intrinsecamente ligados aos aspectos discutidos anteriormente. Concordo plenamente com as autoras que "os desafios para os processos de preparação do "novo" perfil, referem-se aos mecanismos de seleção, aos 
processos de capacitação, aí incluídos os treinamentos introdutórios, a educação continuada e a sistemática de supervisão adotada”. No entanto, acho que urge a implantação de formas mais abrangentes e organizadas de formação e capacitação dos profissionais de saúde, incluindo os ACS, mediante um projeto nacional, estimulado pelo MS, incorporando-se e utilizando experiências existentes, como os Polos de Capacitação de Formação e Educação Permanente dos Profissionais de Saúde da Família e a série de vídeos educativos produzidos numa parceria entre o MS e a Escola de Saúde Pública do Ceará - Agentes em Ação, entre outras. O processo de qualificação do ACS ainda é desestruturado, fragmentado, e, na maioria das vezes, insuficiente para desenvolver as novas competências necessárias para o adequado desempenho de seu papel. Os programas educacionais devem ser elaborados e baseados no desenvolvimento de competências, utilizando métodos de ensino-aprendizagem inovadores, reflexivos e críticos, centrados no estudante, e, quando possível, incluindo novas tecnologias, como a educação à distância. Além disso, dentro desse contexto, o desenvolvimento de algumas competências transversais, como a capacidade em trabalhar em equipe e a comunicação, devem fazer parte de qualquer programa educacional do ACS e dos outros profissionais de saúde.

Em suma, o tema tratado no artigo é complexo, relevante e carece mais discussão. A formação e a qualificação de recursos humanos têm sido grandes entraves para a efetiva consolidação do SUS.

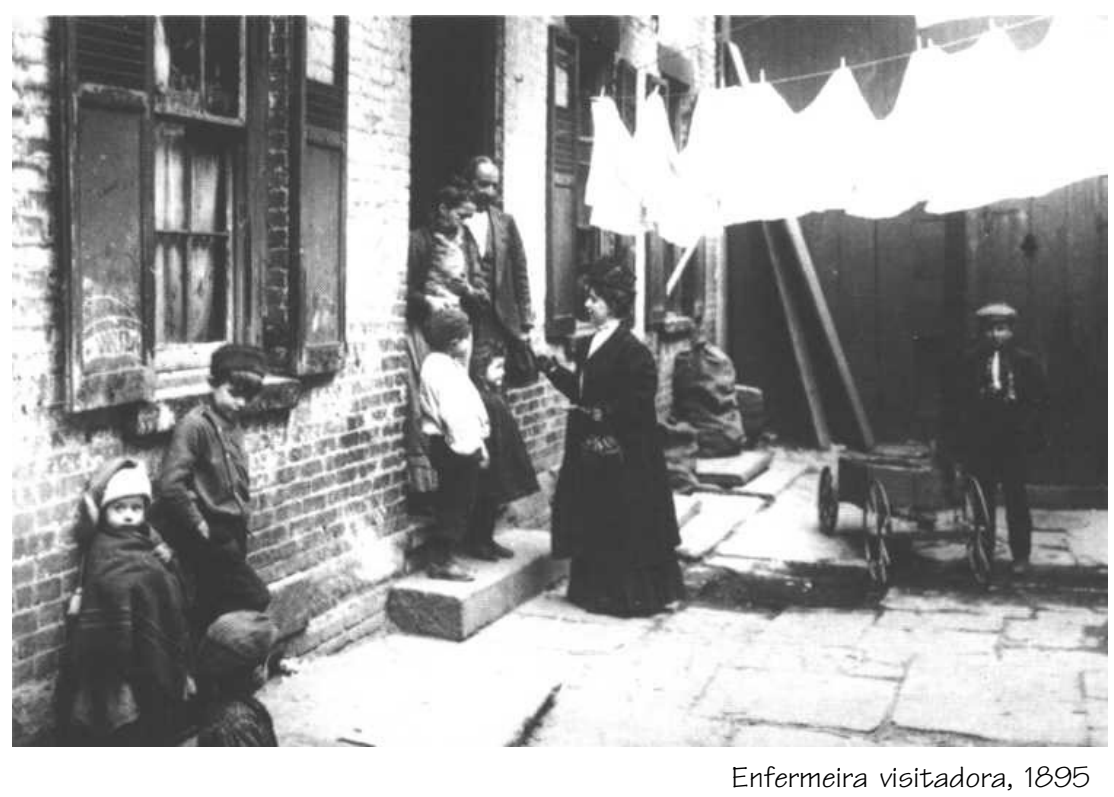

Recebido para publicação em: 15/01/02. Aprovado para publicação em:23/01/02. 